\title{
Model of Fishermen Guidance System (FGS) Based GPS and GSM
}

\author{
Wawan Setiawan \\ Department of Computer Science, Indonesia University of Education \\ wawans@upi.edu
}

\begin{abstract}
This paper is aimed to develop a model navigation and application of Global Positioning System (GPS) and Global System Mobile (GSM) in the model system of the fishing guide. Furthermore, this paper describes what and how a major role in popularizing a fishing guide system model. Modifications that should be made in each unit to get a way to use the GPS and GSM according to fishermen dynamic environment is described. Modifications were made in the system model unit fishing guides also assist in finding a reliable and accurate planimetric solution in the case of poor visibility of GPS and GSM satellite, which is usually common in the fishing environment. In the model system models fishing guide fishing guide system based on GPS and GSM can be successfully implemented in an environment designed for fishermen in developing regions. This, if implemented in a planned will bring a significant increase in the revolutionary Indonesian Fisheries. The Model of Fishermen Guidance System Based GPS and GSM that has been built allowing an institution or an individual to be able to control, monitor and communicate in a geographic coordinate system (map). Validation by experts and users indicate that the system is operationally feasible to use the results of the feasibility level of $87.61 \%$ and $81.67 \%$ of the expert user and both showed good category. The operator will log into the appropriate application access rights are allowed. The resulting device system has several characteristics including: Easy to use (user friendly), Easy to carry (mobile handsets), Informative, Applicative, High Technology, and Network Wide. Based on daily monitoring, coordinate information distributed to the fishermen either via GPS, SMS (Short Massage Services) or through a printed map. Generally the fishermen using a printed map, due to the reading simpler and faster. Performance is based on the acquisition of fish fisherman fishermen after the data supplied koordiant previously, there were no reports that the fishermen do not get fish. With location information of fish that are easily achieved the goal of capturing the fisherman turned fish into taking fish. Basically the fishermen helped with the fish location information from the beginning. Location of fish that are informed by much more than the previous system in which fishermen have fish location data based on experiences.
\end{abstract}

Keywords: Fishermen Guidance System (FGS), Global Positioning System (GPS), Global System Mobile (GSM)

\section{Introduction}

Indonesia is recognized worldwide as the largest archipelagic country in the world, with two thirds of its territory is the sea with an area of 5.8 million $\mathrm{km}^{2}$ consisting of a vast territory with a $3.1 \mathrm{~km}^{2}$ and the ZEEI with an area of $2.7 \mathrm{~km}^{2}$, and consists of 17,504 islands and a coastline of $81,000 \mathrm{~km}$ and contain natural resources, especially biological resources (fish) are abundant and diverse. Utilization of Indonesian marine fish resources in the various regions is uneven. In some waters still open great opportunities for the development of utilization, while in some other regions already reached solid state fishing or overfishing. Fisheries management in the region carried out by regional-owned 
enterprises as the representative of the local Department of Fisheries and Marine Resources. These enterprises should be encouraged to empower the fishermen with both of them to implement a system that can help provide information potential of fish. The system is managed and empowered by enterprises in order to increase the productivity of the fishermen. It can be caused due to the potential management of fisheries resources is not managed in an integrated manner. One reason is the unavailability of data and information regarding potential fishery resources of Indonesia. Lack of data and information leading to potential fisheries can not be used optimally and sustainably. Potential marine, especially in the form of fisheries potential, is one of the huge potential the territory of the Republic of Indonesia. This potential is still largely used by fishermen and equipment utilization is still the conventional method. On the other hand, actually the government through the Ministry of Maritime Affairs and Fisheries, has been disseminating information online, the potential locations of fish in Indonesia. The problem is the information is not biased fully utilized by fishermen. Therefore, it is necessary for a system to help the fishermen to benefit from this information. To support these efforts need to be applied to a system that can help increase the productivity of the fish's arrest. In this study applied the Model of Fishermen Guidance System (FGS) Based GPS and GSM [1]. The model of this system is relatively new as never before. Fishery system there is only limited information system or monitoring system fisherman, and yet accommodate aspects of management. This system model can perform treatment fishermen when they are working. This system model will be able to change the principle of fishermen, from capturing the fish into taking the fish [2].

There are three issues to be resolved in the diffusion of this study. The first problem is how to introduce the characteristics of systems that can assist stakeholders in the fishing area. The second problem is how the system can be understood by all stakeholders in the fishing area well so that the system can be applied easily. The third issue is how the fishing performance after the implementation of the guiding system developed fishermen.

Delivery of location information should be submitted to the fishermen in a digestible form as easy as possible, for example in the form of how many degrees of direction, and how far away from the current position of the fisherman [3]. Application system based fishing guide GPRS, which is compiled with the data distribution of the location of potential fish from the National Institute of Aeronautics and Space Administration and the Ministry of Maritime Affairs and Fisheries, as well as information on the location of fishing vessels which are periodically sent to the control center, will allow for the information needed to make an arrest fishermen fish more effectively and efficiently.

The purpose of this study is to implement a system model that can be used to guide the fishermen at a concentration of fish with GPRS based application [4]. The target of this study is the implementation of a pilot project for the utilization of the developed system, the conventional fisherman who has not utilizing GPS satellite navigation as a tool in the process of fishing.

\section{Reseach Methodology}

Diffusion activities include three (3) phases, namely 1) desing and consolidation of systems, 2) implementation and application of system, and 3) evaluation of system. The three stages of the cycle/set of activities that the diffusion of science and technology implemented comprehensively ranging from collecting data, systems development, and utilization. In order for this system can be fully utilized by users, especially the fishing community, it is done in the form of dissemination of knowledge transfer in the field how to use the system [5].

First phase is preparation activities which include: 1) Implement tracking subsystem fishing vessels, using GPS coordinate data and data communications via satellite, 2) Interpretation and/or distribution of location data conversion potential fish dibarkan by the 
National Institute of Aeronautics and Space Administration and the Ministry of Marine and Fisheries, so it can be integrated into Model of Fishermen Guidance System Based GPS and GSM and plotted in the same coordinate system with the coordinate system used for tracking fishing vessels [6], 3) Conducting periodic spatial analysis to determine the location of the nearest fish concentrations of the location of the fishermen, then transmit the information to the fishermen concerned through SMS (Short Massage Services), and 4) Assist and information on fishing when the relevant planning towards the location of concentrations of certain fish, and turns on the way deviated from the nearest track. Figure 1 is an interaction system model which show the relation betwen facilities are used.

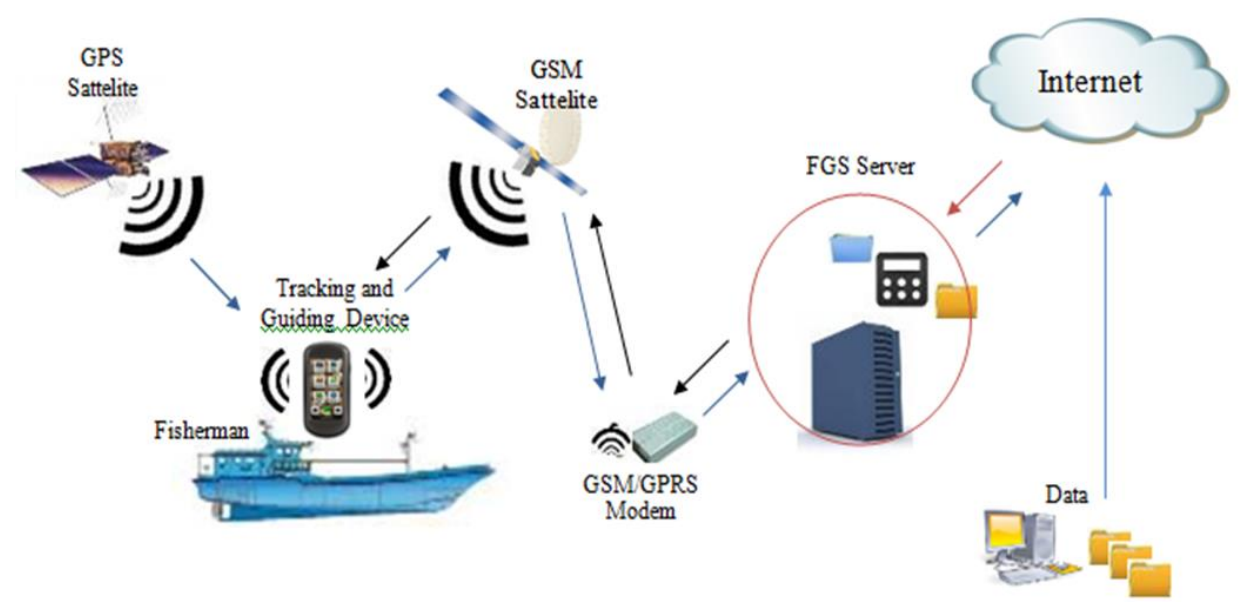

Figure 1. Interaction of System Model

In the process of perfecting this system, which are all used software open source, namely: Linux Operating System, MapServer and OpenLayers to display maps and management, PHP and JavaScript for web programming, Gammu for the purposes of sending SMS (Short Messaging Services). All data related to the system will be stored in a PostgreSQL database, with additional modules to PostGIS spatial data management (base map, trace the location of fishing boats, etc.) [1].

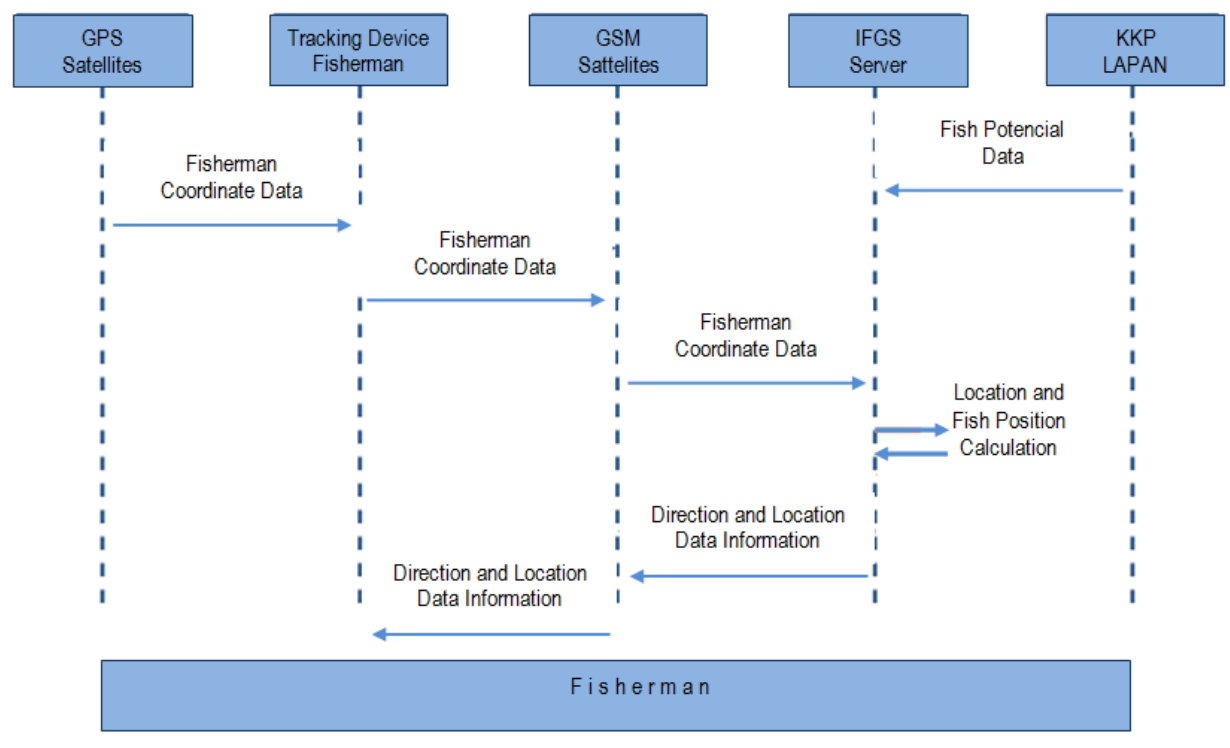

Figure 2. Models of Communication System 
Second phase is the implementation of GPRS based fishing guide systems. Implementation of the system consists of three parts: 1) Socialization and Installation System; 2) Establishment of Field Operations Team; and 3) Training System Usage.

The final phase is monitoring and evaluation of the implementation of the GPRS-based fishing guide systems. This activity performed for two aspects that are operational of guidence system, and the fishermen's performance by the fishermen catch fish obtained.

The validation of the system was conducted by some experts and users with the parameters which consisted the aspects of common aspect (C), aspects of software engineering (SE), and aspects of visual communication (VC) [7].

Evaluation phase was also conducted to see the user's response toward operating system, shortages, excellencies, and other constraints. In this research and development, some of the instruments were used to collect the data needed included questionnaire of exploratory study at the beginning of the study, questionnaire of expert validation on the development phase, and data analysis techniques used were adjusted to the characteristics of the data collected. The data resulted from the questionnaire of survey field (preliminary study) was processed by calculating the frequency of the alternate answers selected by the respondent which was then converted into a percentage and then categorized [7]. The result data of expert validation questionnaire were processed by using weight calculations on rating scale measurement and was compared to the ideal score to obtain the average percentage of the feasibility of the resulting system.

\section{Results and Discussions}

The results of this study were obtained by 3 (three) activity, namely the design and strengthening of systems, system implementation, and evaluation. The design of the system depends on the characteristics of the data and focused on ease of management in order to operate the system running. Implementation of systems aimed at developing user skills (fishing) for the system to be used. Evaluation focused on the performance of the system and fishermen [7].

The results of the first phase of activity is achieved coordination, analysis, design and implementation of the system as well as integration with device tracking fishing vessels.

\subsection{Style of Data}

Navigation systems provide instruction in text format via SMS. Fill in the instruction of the information is the result of processing the data that has been collected as supporting data for direct calculation process where fishing boats fishing in marine waters project area. The data is obtained from reliable sources in relation to coordinate and fisheries. The data are expressed in parameters to determine mobilization fishing. The characteristics of the data is determined on estimates, observations and measurements by several sources that produce a certain output values, so that the calculation can be done to get a decision in a fishing voyage [8].

\subsection{Validation of System}

The validation of system was conducted by some experts and users with the parameters which consisted the aspects of common aspect (C), aspects of software engineering (SE), and aspects of visual communication (VC). The validation results of the system by expert could be shown in the following Table 1 [7]. 
Table 1. Results Validation Experts

\begin{tabular}{cccccc}
\hline Aspect & $\begin{array}{c}\text { Number of } \\
\text { Expert }\end{array}$ & $\begin{array}{c}\text { Number of } \\
\text { Optional }\end{array}$ & $\begin{array}{c}\text { Ideal } \\
\text { Score }\end{array}$ & $\begin{array}{c}\text { Resulted } \\
\text { Score }\end{array}$ & $\%$ \\
\hline C & 3 & 3 & 30 & 26 & 86.67 \\
SE & 3 & 9 & 90 & 80 & 88.89 \\
VC & 3 & 11 & 110 & 96 & 87.27 \\
\hline \multicolumn{5}{c}{ Average } \\
\hline
\end{tabular}

Fishermen were also involved in the validation of the operational systems which the results could be seen as the Table 2 below.

Tabel 2. Results Validation Users

\begin{tabular}{lccc}
\hline \multicolumn{1}{c}{ Aspect } & $\begin{array}{c}\text { Resulted } \\
\text { Score }\end{array}$ & $\begin{array}{c}\text { Ideal } \\
\text { Score }\end{array}$ & \% \\
\hline Navigation keys on the system & & & \\
Navigation keys on the system easily understood & 11 & 15 & 73.33 \\
Navigation keys on the system easily to use & 13 & 15 & 86.67 \\
$\begin{array}{l}\text { System display } \\
\text { System display easily understood }\end{array}$ & 13 & 15 & 86.67 \\
$\begin{array}{l}\text { System display should be interesting } \\
\text { Ease of the system to use }\end{array}$ & 12 & 15 & 80.00 \\
$\begin{array}{l}\text { Guidance fisherman system easily to use } \\
\text { Guidance fisherman system convenient to use }\end{array}$ & 14 & 15 & 93.33 \\
$\begin{array}{l}\text { System interactivity } \\
\text { System interactivity easily understood }\end{array}$ & 11 & 15 & 73.33 \\
$\begin{array}{l}\text { System is interactive in supporting to comprehend the } \\
\text { data }\end{array}$ & 11 & 15 & 73.33 \\
\hline & 98 & 15 & 86.67 \\
\hline
\end{tabular}

Validation by experts and users indicate that the system is operationally feasible to use with the feasibility level of $87.61 \%$ and $81.67 \%$ both of expert and user showed good category [7]. Base on Table 1 and 2, hardware and software that is used as a navigation system in sea fishing boat has some characteristics as follows.

1) Easy to use (user friendly)

Tools and software used in conducting scouting fishing vessels, can be easily learned and understood by the fishermen.

2) Easy to carry (mobile handset)

For the purposes of wider space in the utilization-use tool that can be brought wherever the fishing is traveling around the harbor and boats.

3) Informative

Tools and software used to provide information that is easy and clear navigation on.

4) Applicative

In its application can be optimally used at sea and provide benefits in communication fishing.

5) High Technology.

Tools and software used in the advanced technology-based communication needs in marine navigation systems.

6) Extensive network 
The tools used have a vast communications network especially in its use for the purposes in Republic of Indonesia waters.

Fishing guide system developed modified according to the needs of the field and changed its name Fishermen Guidance System (FGS) Based GPS and GSM with http://www.sipanenikan.com site address show as Figure 3 [6]. The site displays a map containing the location of the potential of the average fish goes for three days. Potential location coordinates of marked fish with fish images consisting of images of fish in green, yellow, and red. Figure of fish with green color indicates the coordinates of potential fish current (today), yellow fish show the coordinates of potential fish one day ago (yesterday), and red fish show the coordinates of potential fish two days ago (the day before yesterday). Data potency fish only for Indonesian catchment area obtained from the National Institute Aeronautics and Space (LAPAN) Republic of Indonesia.
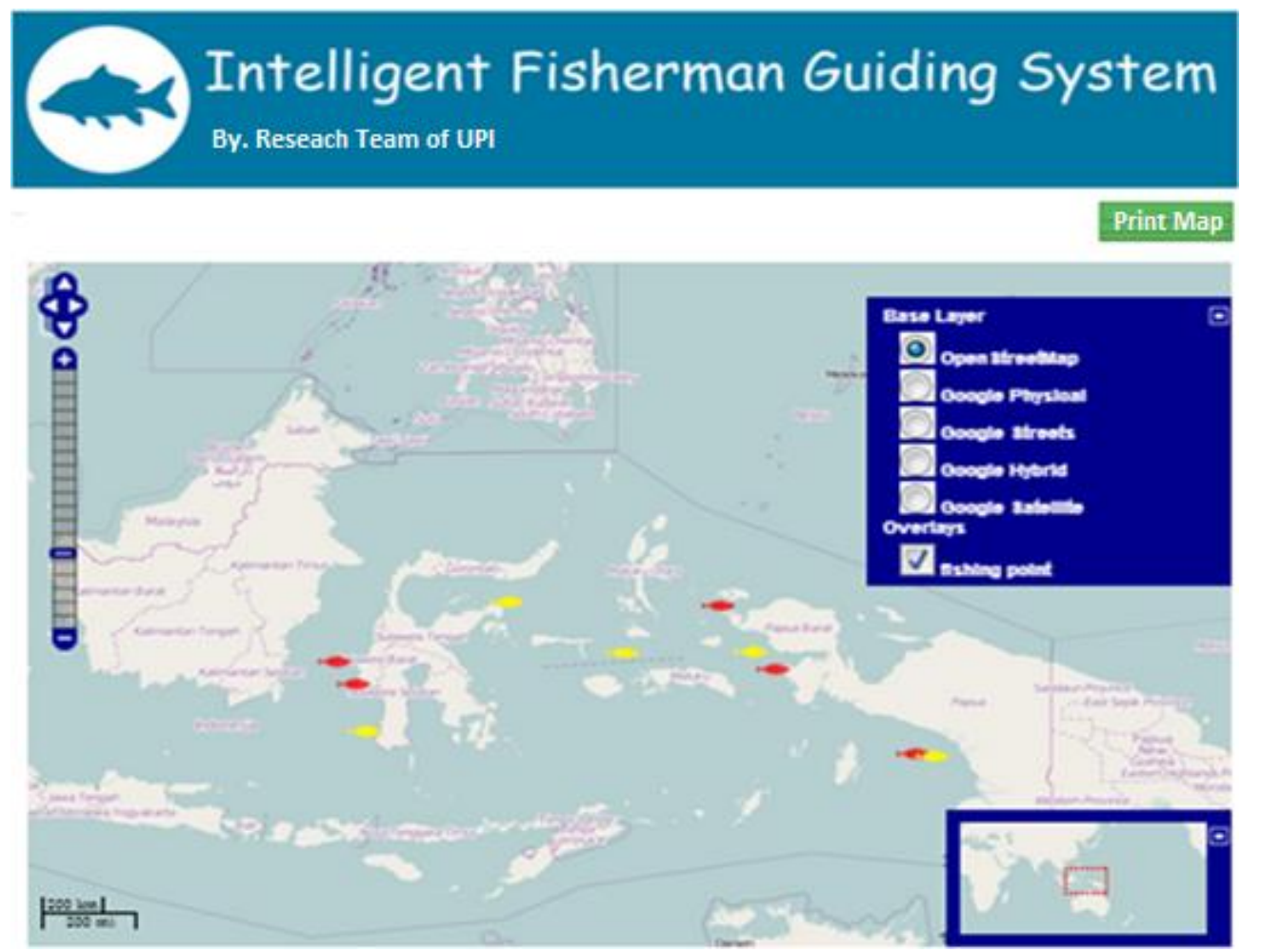

Figure 3. Main Menu of Intelligence Guidance Fisherman System

Developed communication takes place periodically via SMS text format that is sent contains instructions that will position fishing location can be visited. The application of satellite technology that provides the type of Garmin GPS communication network coverage is very broad, especially for the location of the territory of Indonesia.

Communication at sea took place in two conditions, namely when the object (fishing boats) will be dispatched from the port (starting point) to the nearest fishing location, and when the object is on the way to the waters of the nearby switch to localized arrest of other arrests have been determined according to the instructions through the system navigation [9].

The pattern of communication is done between the operator and the user. The operators perform related data collection and entry via the navigation system application, then the processing and calculations performed on the application server, the result of calculations determines the location of the fish in the fishing inform the user, in this case the operator acts as a navigator users (fishermen) in catch fish [9]. The results of the second phase is 
achieved is an understanding of all parties/elements of the purpose and empowerment systems.

\subsection{Pilot Project}

South Halmahera enterprises as partners, formed a team to manage the system guides the fishermen. Technically managing fishing guide system aided by the implementing partners Polytechnic of Halmahera. Formation of field operations team is an attempt to escort / accompany the implementation of a system for fishermen on the field. Operational team consists of three (3) parties: Polytechnic Halmahera, Prima Commercial Enterprises, and Coordinator of the Fishermen. Polytechnic of Halmahera placing student personnel as well as a field of practice activities. Commercial Prima Enterprises parties to cross check the accuracy of the coordinates through the reporting of fish catches. Operators fisherman is a fisherman who can mediate with other fishermen. Third party do operators guidance as synergies. Polytechnic of Halmahera perform more guidance operational to technology system used, Prima Enterprises Commerce more guidance to the completeness of the field setting. Coordinator fishermen make arrangements coordination with fishermen.

\subsection{Training of System}

Training the use of systems application emphasized by Polytechnic Halmahera and Prima Enterprises Commerce. While fishermen as end users are not overly burdened with system operational issues but they are directed to how the understood what the system generated that are catchment maps and how to achieve it. Through a variety of elements related synergies, it will be enable that the system can be powered by either [3].

The results achieved the final stage is the monitoring and evaluation of the implementation of the system. Monitoring and evaluation activities are directed at two (2) aspects that are the system's operational, and fishermen's performance.

System performance is supported by the synergy of all parties involved in this system as shown in Table 3 as an activity to use the system.

Tabel 3. Activity System

\begin{tabular}{|c|c|c|c|c|c|}
\hline No. & $\begin{array}{c}\text { Function/ } \\
\text { Treatment/Activities }\end{array}$ & $\begin{array}{l}\text { Base } \\
\text { Station }\end{array}$ & $\begin{array}{c}\text { Data } \\
\text { Supplier }\end{array}$ & $\begin{array}{l}\text { Point } \\
\text { Center }\end{array}$ & Fisherman/User \\
\hline 1 & Satellite Selection & $\sqrt{ }$ & - & - & - \\
\hline 2 & $\begin{array}{l}\text { Signal Search and } \\
\text { Acquisition }\end{array}$ & - & - & - & $\sqrt{ }$ \\
\hline 3 & Code and Carrier Tracking & - & - & - & $\sqrt{ }$ \\
\hline 4 & Data Demodulation & $\sqrt{ }$ & - & - & - \\
\hline 5 & $\begin{array}{l}\text { Satelit Position } \\
\text { Computation }\end{array}$ & $\sqrt{ }$ & - & - & - \\
\hline 6 & $\begin{array}{l}\text { Atmospheric Model } \\
\text { Compuation }\end{array}$ & $\sqrt{ }$ & - & - & - \\
\hline 7 & Navigation Solution & $\sqrt{ }$ & - & - & - \\
\hline 8 & Coordinates Data & $\sqrt{ }$ & $\sqrt{ }$ & - & - \\
\hline 9 & Use Data & & - & - & $\sqrt{ }$ \\
\hline 10 & Share Data & $\sqrt{ }$ & - & - & $\sqrt{ }$ \\
\hline 11 & Update Data & $\sqrt{ }$ & $\sqrt{ }$ & - & - \\
\hline 12 & Waypoint Managing & $\sqrt{ }$ & - & - & $\sqrt{ }$ \\
\hline 13 & Map Managing & $\sqrt{ }$ & $\sqrt{ }$ & $\sqrt{ }$ & $\sqrt{ }$ \\
\hline 14 & News Management & $\sqrt{ }$ & - & & - \\
\hline 15 & Read News & $\sqrt{ }$ & $\sqrt{ }$ & $\sqrt{ }$ & $\sqrt{ }$ \\
\hline 16 & Reporting Result & $\sqrt{ }$ & - & $\sqrt{ }$ & $\sqrt{ }$ \\
\hline
\end{tabular}




\section{1) System Performance}

Coordinate system is updated whenever there is a new coordinate data obtained, a maximum of 3 (three) days by the coordinate data suppliers Space agency either directly through the access facilities owned or sended to the admin center (base station). Updates are also performed by the coordinate data center admin who uses the data through the first stage of data adjustment [7].

The position coordinates on the map display, characterized by images of fish green, yellow, and red indicates the coordinates of each today, a few days ago, and two days ago. Based on daily monitoring, coordinate information distributed to the fishermen either through SMS or through a printed map [1]. Generally the fishermen using a printed map, due to the reading simpler and faster. In general, the system can run and inform the locations of potential fish basically widely [9].

\section{2) Fishermen Performance}

Basically the fishermen helped with the fish location information from the beginning. Location of fish that are informed by much more than the previous system in which fishermen have fish location data based on experience. Performance is based on the acquisition of fish fishermen still difficult to conclude, however there are more things to that observed after the fishermen koordiant the data supplied previously, there were no reports that the fishermen do not get fish. Earlier in the day there was always a fisherman who does not get caught fish [6].

\subsection{Testing of System}

\section{1) System Performance}

The key significance is the system is the latest information necessary fishing communities. Information in the form of discourse that can be loaded in the news pages that the system can also be deployed printout by center points. This discourse information can be used as an effort to increase insight or knowledge of the fishermen on matters relating to the general and specific life as a fisherman [6].

The most important information is the location of fish as a major destination for fishermen. The system can provide information on the location of fish in general but does not yet have the ability to give the fish the quantity of information contained in the site. For the fisherman started toward the closest location first, if the quantity of fish is low, fishermen towards other locations in sequence [6].

\section{2). Fisherman Performance}

The better performance if the fishermen catch more fish (large). To get more fish with relatively low cost location information is needed right fish and easily accessible so that the goal of capturing the fisherman turned fish into taking fish. The system still has flaws that have not gave the obstacles along the track information such as storms or dangerous waves. However the experienced user, the fishermen have to have a data area that is difficult (dangerous). Performance is also determined by the fishermen who owned fishing, fishing generally have the engine (boat) with little capability average 5-10 GP. It is an obstacle to a remote location where require machines with capabilities in over $10 \mathrm{GP}$ [5].

Another thing that affects to the performance is fishing sytem is the ability/qualification of fishermen itself. Fishermen are generally less educated and some have not finish of primary education. It is caused also by the occurrence of a change of mindset in which the profession of civil servants has become the main hope of the family so that fishermen have a higher education qualification is sought first selecting civil servants. 


\section{Concluding Remarks}

Model of Fishermen Guidance System (FGS) Based GPS and GSM that has been built allowing an institution or an individual to be able to control, monitor and communicate in a geographic coordinate system (map). The operator will log into the appropriate application access rights are allowed. Validation by experts and users indicate that the system is operationally feasible to use the results of the feasibility level of $87.61 \%$ and $81.67 \%$ of the expert user and both showed good category. The resulting device system has several characteristics including: Easy to Use (user friendly), Easy to Carry (mobile handsets), Informative, Applicative, High Technology, and Network Wide.

Based on daily monitoring, coordinate information distributed to the fishermen either via GPS, SMS or through a printed map. Generally the fishermen using a printed map, due to the reading simpler and faster. Fishermen's performance is based on the acquisition of fish after the coordinate data supplied previously, there were no reports that the fishermen do not get fish. With location information of fish that are easily achieved, then the goal of capturing the fisherman turned fish into taking fish.

The system needs to provide information on the location of fish along with fish quantity information. The system needs to be developed to be able to not give information about the obstacles along the path like a storm or waves dangerous. Performance fishermen can also be improved by increasing the engine / boat used. The fishermen should be enlightened on a regular time about the technology and productivity opportunities. Regeneration fishermen also should receive attention and ongoing programs. The application developed easy to use (user friendly), portability (mobile handsets), informative, applicable, and an extensive network.

\section{Acknowledgement}

Research activities supported by several parties and personnel who contributed to the thoughts, ideas and concrete action to software development, in particular we would like to thank the Research and Technology Ministery Republic of Indonesia, and the Aplication Remote Sensing Centre of Republic of Indonesia has provided information and knowledge arrest potential zones fish.

\section{References}

[1] P. K. Harshadbha, "Design of GPS and GSM Based Vehicle Location and Tracking System", International, Journal of Science and Research (IJSR), India Online ISSN: 2319 -7064, (2013).

[2] K. V. Barai and R. M. Samant, "GPS/GPRS based system for vehicle tracking and traffic management", ICWET'11 Poceeding of the International Conference \& Workshop on Emerging Trends in Technology, (2011).

[3] I. M. Almomani, N. Y. Alkhalil, E. M. Ahmad and R. M. Jodeh, "Ubiquitous GPS Vehicle Tracking and Management System", Applied Electrical Engineering and Computing Technologies (AEECT), 2011, IEEE Jordan Conference on, (2011), pp. 1,6.

[4] J. Padmanabhan, "GPS Based Vehicle Tracking System", the Asian Conference GPS, (2001).

[5] Stoddart, "Open Architecture", A New Concept in Vehicle Location Syslems, Proceedings of Ion Gps; 7//v1; 491-499 ION GPS-94, (1994).

[6] Muruganandham and P. R. Mukesh, "Real Time Web Based Vehicle Tracking using GPS", World Academy of Science, Engineering and Technology, (2010).

[7] K. Jain and R. Goel, "GPS Based Low Cost Intelligent Vehicle Tracking System (IVTS)", International Conference on Traffic and Transportation Engineering (ICTTE 2012), IPCSIT (2012) () (2012) IACSIT Press, Singapore, vol. 26, (2012).

[8] A. khan and R. Mishra, "GPS - GSM Based Tracking System", Electronics and Telecommunication Engineering Department, International Journal of Engineering Trends and Technology, vol. 3, no. 2, (2012).

[9] P. Fei, Z. Wenzheng, M. H.-e-Haider, L. Zhongkan and J. Qishan, "Intelligent Land-Vehicle Navigation System using GPS", International Conference on Traffic and Transportation Engineering (ICTTE 2012), (2000). 
[10] M. N. Kulkarni and V. S. Choudhary, "GPS: Intelligence Vehicle Homane System (IVHS)", the Asia GPS Conference, (2001).

[11] P. Herron, C. Powers and M. Solomon, "Global positioning technology in the intelligent transportation space", Motorola Inc., USA.

[12] P. Fei, Z. Wenzheng, M. H.-e-Haider, L. Zhongkan and J. Qishan, "Intelligent Land-Vehicle Navigation System using GPS", GPS, (2000).

[13] M. P. Paine, N. Magedara and I. J. Faulks, "Expediting The Road Safety Benefits of Intelligent Vehicle Technologies-Part 1: Main Report", Report to the Transport Accident Commission of Victoria, NSW: Vehicle Design \& Research/Safety and Policy Analysis International, Ingo Malchow, Webdesign Neustrelitz, (2008).

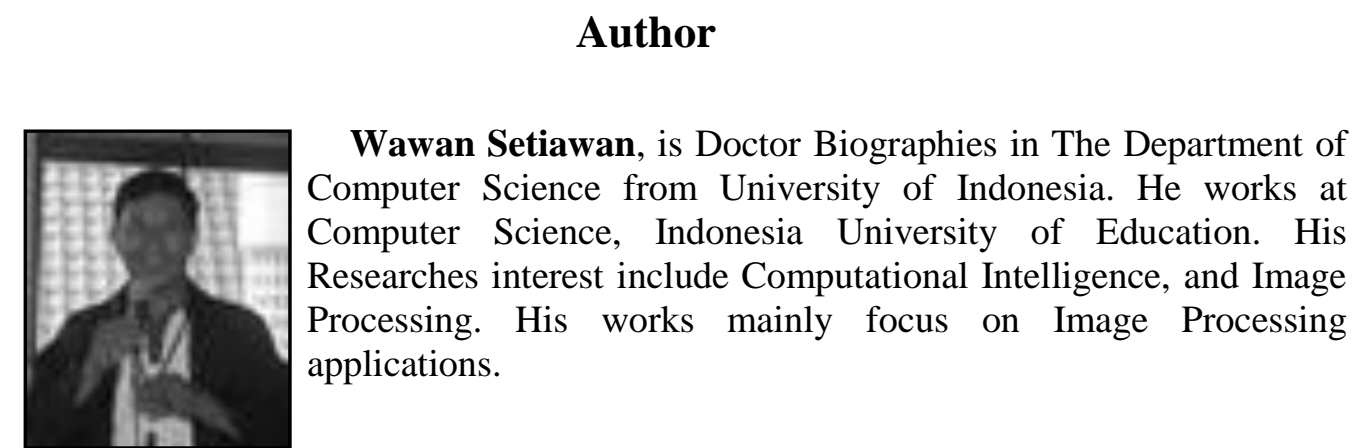

